Research Article

\title{
Impact-Induced Liquefaction Mechanism of Sandy Silt at Different Saturations
}

\author{
Heng Li, ${ }^{1}$ Zhao Duan $\mathbb{D}^{2}{ }^{2}$ Chenxi Dong, ${ }^{2}$ Fasuo Zhao, ${ }^{1}$ and Qiyao Wang ${ }^{3}$ \\ ${ }^{1}$ College of Geological Engineering and Surveying, Chang'an University, Xi'an 710054, China \\ ${ }^{2}$ College of Geology and Environment, Xi'an University of Science and Technology, Xi'an 710054, China \\ ${ }^{3}$ College of Civil Engineering, Chang'an University, Xi'an 710054, China
}

Correspondence should be addressed to Zhao Duan; duanzhao@xust.edu.cn

Received 7 December 2020; Revised 25 February 2021; Accepted 17 March 2021; Published 30 March 2021

Academic Editor: Xinbao Yu

Copyright ( $92021 \mathrm{Heng} \mathrm{Li}$ et al. This is an open access article distributed under the Creative Commons Attribution License, which permits unrestricted use, distribution, and reproduction in any medium, provided the original work is properly cited.

\begin{abstract}
Landslide-induced liquefaction has received extensive attention from scholars in recent years. In the study of loess landslides in the southern Loess Plateau of Jingyang, some scholars have noted the liquefaction of the near-saturated sandy silt layer that is caused by the impact of loess landslides on the erodible terrace. The impact-induced liquefaction triggered by landslides is probably the reason for the long-runout landslides on the near-horizontal terrace. In order to reveal the mechanism of impactinduced liquefaction, this paper investigates the development of pore pressure and the impact-induced liquefaction of sandy silt under the influence of saturation through laboratory experiments, moisture content tests, and vane shear tests. It has been found that both the total pressure and pore water pressure undergo a transient increase and decrease at the moment of impact on the soil, which takes $40-60 \mathrm{~ms}$ to complete and only about $20 \mathrm{~ms}$ to arrive at the peak. Moreover, silty sand with a saturation of more than $80^{\circ}$ was liquefied under the impact, and the liquefaction occurred in the shallow layer of the soil body. The shear strength of the liquefied part of the soil is reduced to $1.7 \sim 2.8 \mathrm{kPa}$. Soils with lower saturation did not liquefy. The mechanism of the impactinduced liquefaction can be described as follows: under impact, the water in the soil gradually fills the pores of the soil body as the pore size decreases, and when the contact between the soil particles is completely replaced by pore water, the soil body loses its shear strength and reaches a liquefied state. Soils in the liquefied state have a very high permeability coefficient, and the water inside the soil body migrates upward as the particles settle, resulting in high-moisture content in the upper soil.
\end{abstract}

\section{Introduction}

Liquefaction is described as a phenomenon in which the shear strength of a soil body is reduced due to increased pore water pressure when it is subjected to monotonic, cyclic, or constant volume dynamic loads [1]. When a landslide occurs, the slide will impact, rub, and sometimes liquefy the bed as it slides [2-5]. The phenomenon of liquefaction caused by landslides has received much attention from scholars in recent years [6-9]. Landslides which trigger liquefaction often result in significant loss of life and property damage. For example, the 1983 Saleshan landslide killed 237 people [10], the 2014 Oso landslide killed 43 people [11-14], the 1999 Hiroshima landslide and mudslide killed 24 people [3], and the 2011 Honokidaira landslide killed 10 people [15]. The economic loses such as the destruction of houses and roads were also heavy.

In recent studies on loess landslides in the southern plateau of Jingyang, some scholars have noted the impact of loess landslides on the erodible terrace layer and the liquefaction of the near-saturated sandy silt layer caused by the impact $[2,16-18]$. The impact-induced liquefaction during the sliding process is probably the driving force behind the high speed and long runout of these landslides on nearhorizontal terraces $[2,19-21]$, but the mechanism of this effect is not yet well understood. Pore water pressure, which plays a crucial role in the liquefaction process, is most affected by the saturation of the soil [22]. Therefore, in order to propose a liquefaction mechanism under impact, this paper focuses on the following three research objectives: (1) the 
development of pore water pressure under impact; (2) the liquefaction characteristics of sandy silt soils under the influence of saturation; and (3) the revealing of the mechanism of impact-induced liquefaction. These objectives will help to reveal the mechanics of the movement process of this type of landslide, which in turn will help to predict their sliding distance.

1.1. Geological Background. The southern Loess Plateau of Jingyang is located on the right bank of the Jing River in the province of Shaanxi. It has been subjected to strong lateral erosion by the Jing River, resulting in the formation of high and steep slopes [23]. As a result of years of irrigation, loess flow slides have repeatedly occurred in this area, causing many casualties and economic loses [16, 20, 23].

The Miaodian landslide was a loess landslide that occurred on May 27, 2015, in the Loess Plateau of southern Jingyang. As shown in Figure 1(a), the slope has a difference in elevation of 80 meters (from 385 meters at the toe to 465 meters at the top). The landslide deposits have a maximum width of about 330 meters and a length of about 350 meters, undulating forward in a wave-like pattern from the rear edge. The slide mass volume is about $7.26 \times 10^{6} \mathrm{~m}^{3}$, covering an area of about $7.07 \times 10^{4} \mathrm{~m}^{2}$. It is a typical long-runout flow slide [17].

The apparent friction coefficient of a landslide is calculated as the ratio between fall height and horizontal travel length $H / L$, while the apparent friction angle is the value of the inverse tangent function of the apparent friction coefficient. The internal friction angle is the inclination of the shear strength line in the $\sigma-\tau$-coordinate plane. For loose particle materials, the value of the apparent friction angle is often close to the value of the internal friction angle. Therefore, the comparison between the apparent friction angle and the internal friction angle is sometimes used to make a preliminary determination as to whether liquefaction has occurred in a landslide. When the apparent friction angle is less than the internal friction angle of the soil, it indicates that there may be an effect of reducing frictional resistance during sliding, such as the generation of pore water pressure (liquefaction) [24]. The value of the apparent friction angle of the Miaodian landslide is $10.9^{\circ}[2,25,26]$, and the internal friction angle of the saturated loess is about $30^{\circ}$ [24]. Therefore, it can be suggested that there is a possibility of liquefaction during the sliding process of this landslide.

During the field investigation, sand boiling was found in several places in the slip (as shown in Figures 1(b)-1(d)), which is typical of liquefaction $[27,28]$. The traces of these sand boiling points on the surface of the landslide are usually circles or ellipses with diameters ranging from 1 to 1.5 meters. In order to better understand the liquefaction phenomenon under the impact of the landslide, several $1.5 \mathrm{~m} \times 2 \mathrm{~m}$ trenches were made at multiple sand boiling points to a depth of $2.5 \mathrm{~m}$. A $7 \mathrm{~m}$ deep exploratory trench was drilled $150 \mathrm{~m}$ east of the landslide to obtain stratigraphic relationships, groundwater level depths, and to take soil samples for testing. The groundwater level depth in the trench was $5 \mathrm{~m}$.
Observation of the trench at these locations showed that the sandy silt that came up to the surface of the landslide mass was not part of the landslide mass itself; rather, it came from a layer of sandy silt in the lower part of the sliding surface (the upward flow path of this sandy silt layer after liquefaction is shown in Figures 1(e) and 1(f)). The thickness of the sandy silt layer was about $30 \mathrm{~cm}$. As judged by the field, the sandy silt soil in its original state was loosely structured, poorly connected, and prone to spalling.

\section{Materials and Methods}

2.1. Experiment Setup. In this paper, we focus on the soil pressure, pore water pressure, moisture content, and shear strength changes at different depths before and after the impact experiment. Changes in the total pressure and pore water pressure were determined by the impact experiment, while changes in the moisture content and shear strength were determined before and after the impact experiment. The before-and-after changes in moisture content and shear strength were not obtained from the material of one preparation, but from the parallel experiments of two preparations (one impacted and one nonimpacted), as shown in Table 1.

2.2. Experimental Instruments. The impact test system consists of a specimen pressing device, a soil sample container, a cover plate, 3 micrototal pressure sensors, 3 pore water pressure sensors, an impact column, a collar, a data acquisition system, etc. (see Figure 2).

The soil sample container is a bucket with an inner diameter of $30 \mathrm{~cm}$ that carries the soil samples during sample preparation and testing (see Figure 2(b)). Three pore water pressure sensors and three soil pressure sensors can be mounted on each side of the container.

The impact column is a cylinder and weighs $20.87 \mathrm{~kg}$. It has a diameter of $24 \mathrm{~cm}$ and is equipped with four strips of mat. In the experiment, the impact column was released after being pulled up to the designated height by a fixed pulley to impact the soil inside the soil container (see Figure 2(d)).

The collar is mounted above and aligned with the soil container. It restrains the horizontal displacement and twisting of the impact column so that it can only move in a vertical direction, ensuring that the impact column impacts the center of the soil sample vertically. The collar is about $1 \mathrm{~m}$ high and has the same inner diameter as the soil container. 32 vents are designed in the wall; therefore, the friction between the column and the collar is negligible in the experiment.

Three pore water pressure sensors and three micrototal pressure sensors (see Figure 2(c)) were installed symmetrically on both sides of the soil sample container at depths of $5 \mathrm{~cm}, 15 \mathrm{~cm}$, and $25 \mathrm{~cm}$, respectively. The measuring ranges of the pore water pressure sensors and the micrototal pressure sensors are $170 \mathrm{kPa}$ and $600 \mathrm{kPa}$, respectively. The micrototal pressure sensors were installed before sample installation, and the waterproof plugs were replaced by the pore water pressure sensors between impact and soil sample 


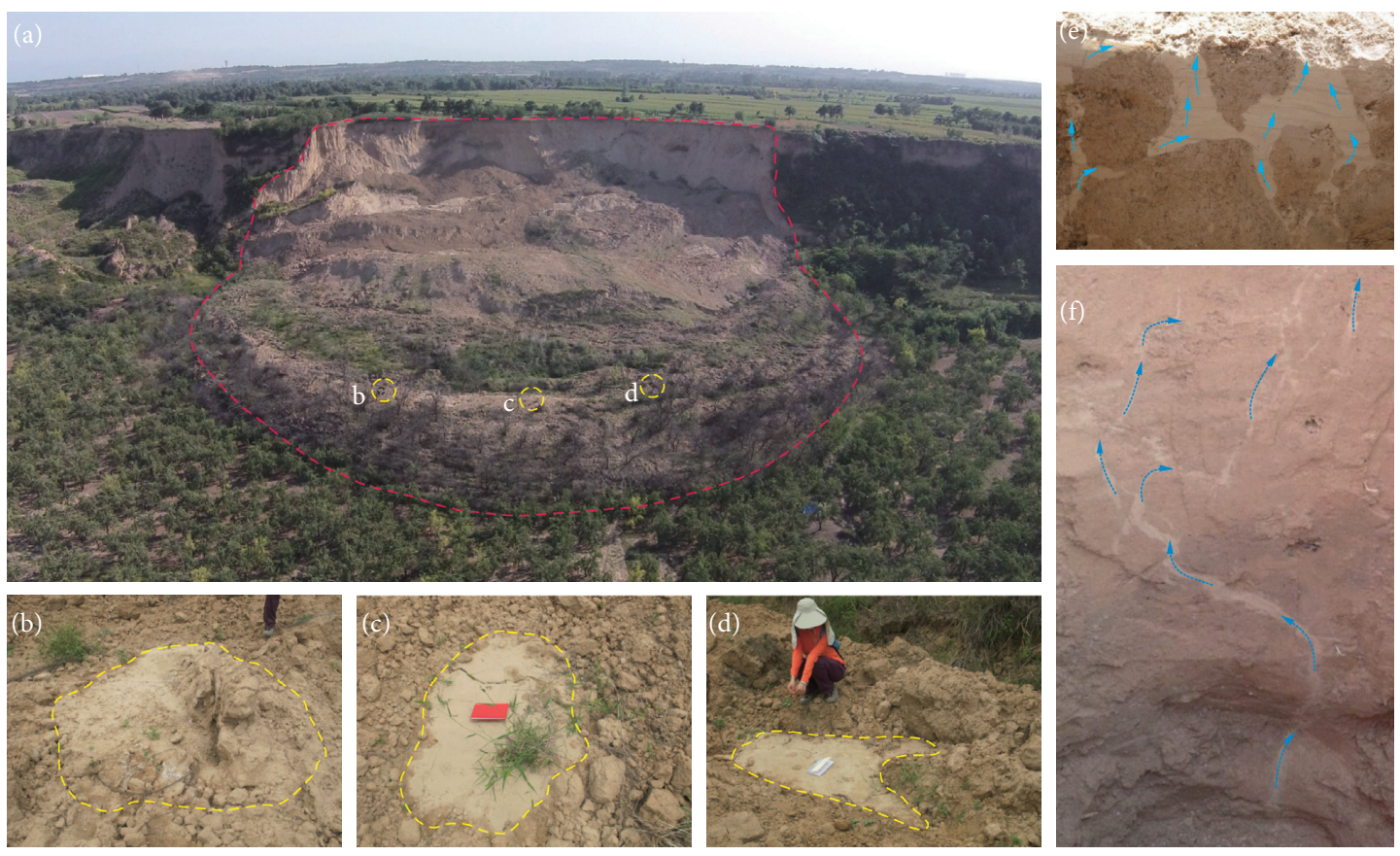

Figure 1: A typical Jingyang landslide and some liquefaction phenomena. (a) Drone view of a typical Jingyang landslide. (b), (c), and (d) Photographs of some traces of sand boiling from liquefaction. (e) and (f) Profiles of the sand boil at (d) obtained by trenching.

TABle 1: Design experimental scheme.

\begin{tabular}{|c|c|c|c|c|}
\hline \multirow{2}{*}{ Specimens } & \multirow{2}{*}{ Test content } & \multicolumn{3}{|c|}{ Depth } \\
\hline & & $5 \mathrm{~cm}$ & $15 \mathrm{~cm}$ & $25 \mathrm{~cm}$ \\
\hline \multirow{2}{*}{ No impact } & Moisture content test & $\mathrm{W} 1 \sim \mathrm{W} 5$ & W6 W10 & W11 W5 \\
\hline & Vane shear test & $\mathrm{V} 1 \sim \mathrm{V} 5$ & V6 V10 & $\mathrm{V} 11 \sim \mathrm{V} 15$ \\
\hline \multirow{4}{*}{ Impact } & Total pressure & S1 & S2 & S3 \\
\hline & Pore water pressure & $\mathrm{P} 1$ & $\mathrm{P} 2$ & P3 \\
\hline & Moisture content test & $\mathrm{W}^{\prime} 1 \sim \mathrm{W}^{\prime} 5$ & $W^{\prime} 6 \sim W^{\prime} 10$ & $\mathrm{~W}^{\prime} 11 \sim \mathrm{W}^{\prime} 15$ \\
\hline & Vane shear test & $V^{\prime} 1 \sim V^{\prime} 5$ & V'6 V'10 & $V^{\prime} 11 \sim V^{\prime} 15$ \\
\hline
\end{tabular}

preparation. The data acquisition frequency of the data collector was $50 \mathrm{~Hz}$ (50 data per second). Each sensor was calibrated before installation to ensure data accuracy. The pore water pressure sensors were calibrated by elevating the water head pressure, and the results were very accurate within the range, with an error of less than $1 \%$. The calibration of the total pressure sensor was carried out in a customized calibrator with a step-by-step loading method on the experimental soil sample. The calibration results show that the results of the sensor within $100 \mathrm{kPa}$ match the true value with an error of less than $3 \%$, but as the load increases, the data obtained are gradually smaller than the true value. Since the experimental data in this paper are less than 100 , the results meet the accuracy requirements. Moreover, through validation by repeated testing, the data collected in the final test is stable and reliable.

\section{Materials}

The sample of sandy silt used in the impact experiment was taken from the trench located $150 \mathrm{~m}$ east of the landslide. The sandy silt layer was buried at a depth of $4.5 \mathrm{~m}$. The particle size classification of the sandy silt is shown in Figure 3, and the basic properties are shown in Table 2.

3.1. Soil Sample Preparation. The sandy silt collected from the site was subjected to drying and sieving procedures and then packed into buckets in layers according to the porosity ratio of the intact soil tested in advance. The soil was pressed in 6 layers of $5 \mathrm{~cm}$ each (see Figure 2(a)) with a total thickness of $30 \mathrm{~cm}$. There was a minimum of $30 \mathrm{~min}$ of static pressing time for each layer and $60 \mathrm{~min}$ of pressing time for the last layer. After each layer was pressed, the surface was groomed so that there was a natural transition between the layers without obvious delamination boundaries.

After the soil samples were pressed, the sample was covered with a pressing board and was ready for infiltration (see Figure 2(b)). The saturation levels of the designed specimens were $65 \%, 70 \%, 75 \%, 80 \%, 85 \%$, and $90 \%$. After calculating the mass of water required, water was infiltrated into the sample through the holes on the pressing board. The air valve at the bottom of the soil sample container was opened, and the cover plate was put on to prevent evaporation until the soil sample was fully infiltrated. The pressing 

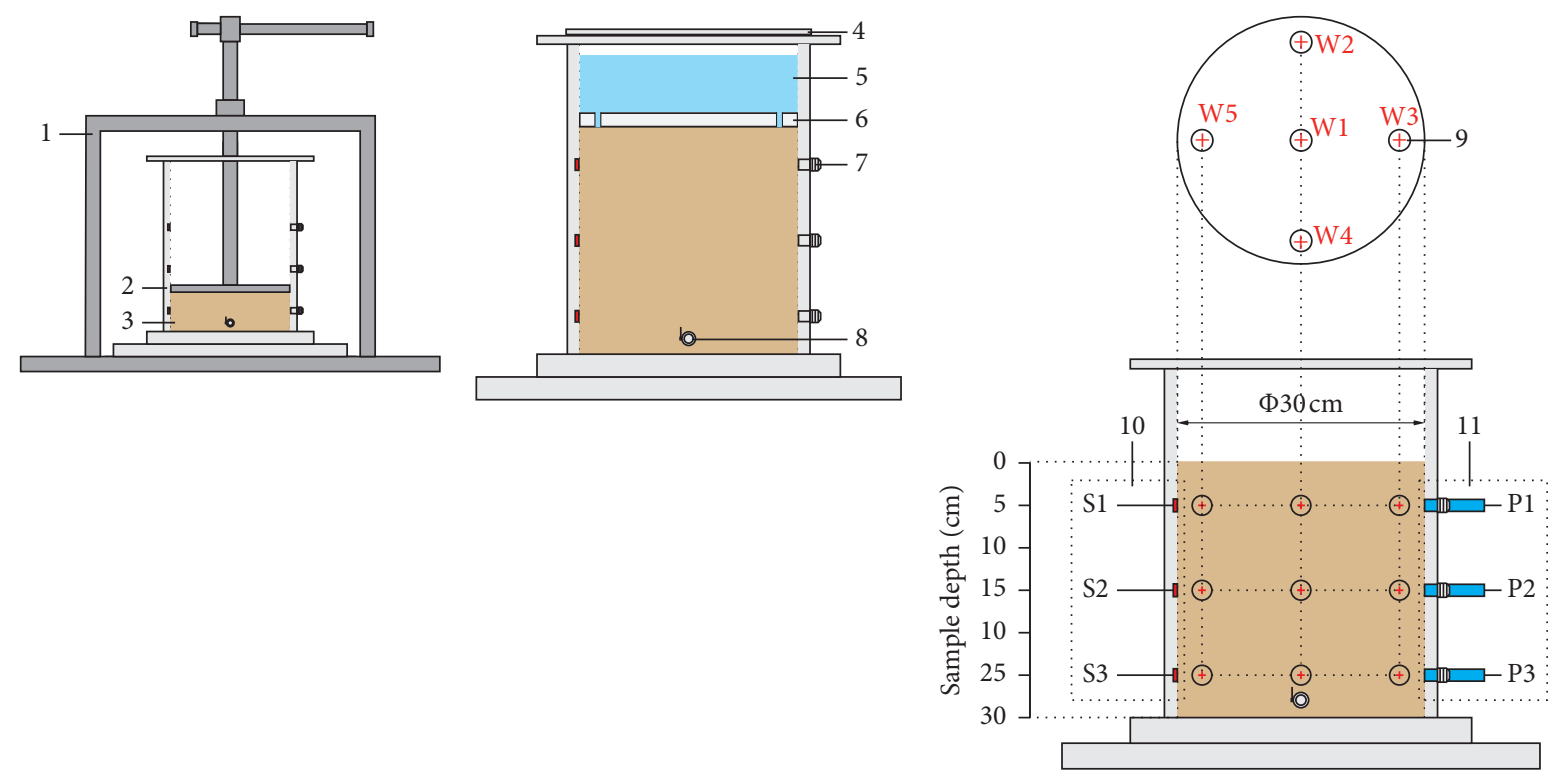

(a)

(b)

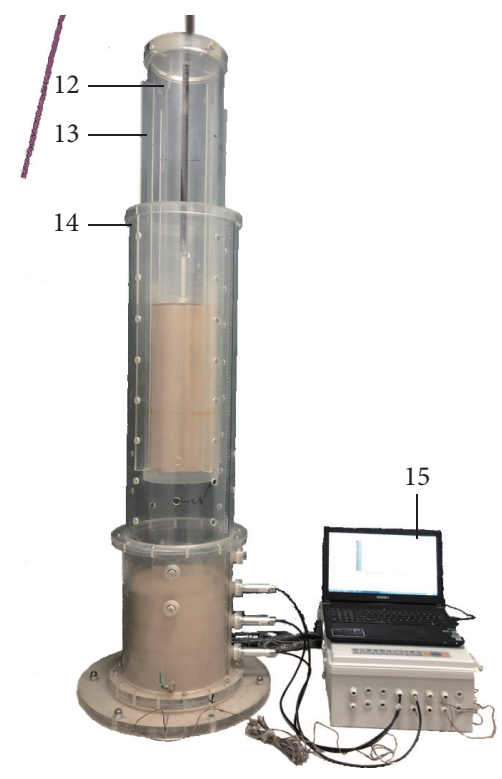

(c)

(d)

FIGURE 2: (a) Schematic of specimen pressing. (b) Schematic of percolation process. (c) Schematic of test points. (d) Image of the experiment instrument installed.

board was not unloaded during infiltration to ensure that the sandy silt samples were neither stressed nor deformed during the process.

After specimen preparation, the test can be conducted. Two sample preparations are needed for each saturation level. After the first sample preparation, the moisture content and shear strength are tested directly without impact. In this test, the shear strength parameters are acquired at $5 \mathrm{~cm}, 15 \mathrm{~cm}$, and $25 \mathrm{~cm}$ depths by vane shear tests, without taking out soil samples (see Figure 2(c)). The procedure of vane shear test is using a standard cross-plate probe inserted into the soil and twisting it at a certain rate to measure the undrain shear strength. The following should be noted in the test process: (1) cross-plate probe should be fixed for 2 3 min after inserting to the test depth before starting the test; (2) torsional shear rate is generally $\left(1^{\circ} \sim 2^{\circ}\right) / \mathrm{s}$, and should continue to measure $1 \mathrm{~min}$ after reaching peak strength; and (3) the shear strength should be measured with an accuracy of $1 \sim 2 \mathrm{kPa}$. After that, the soil sample is dug out at the same location in each layer for moisture content tests. After repeating the sample preparation several times, the porosity and saturation of the soil measured shown that the error of the porosity was within 0.05 and the average error of the saturation was about $2 \%$. This error is acceptable in this experiment, considering that such an error also exists in the field. The impact was performed after the second sample 


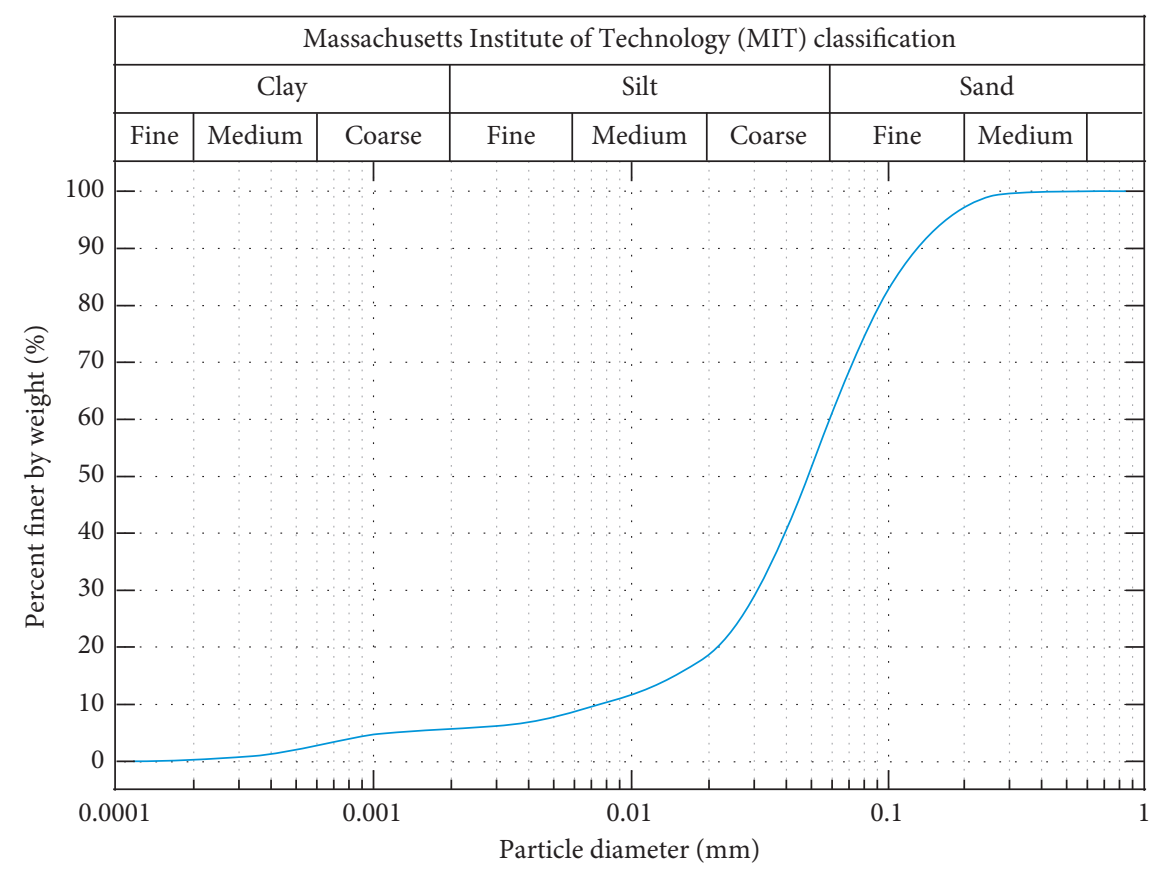

FIGURE 3: Representative particle size distribution curve of the liquefied soil.

TABLE 2: Basic physical properties of the liquefied sandy silt.

\begin{tabular}{lc}
\hline Property & Sandy silt \\
\hline Specific gravity & 2.70 \\
Initial moist bulk density $\left(\mathrm{g} / \mathrm{cm}^{3}\right)$ & 1.81 \\
Initial moisture content $(\%)$ & 25.2 \\
Initial saturation $(\%)$ & 80.1 \\
Initial void ratio & 0.85 \\
Liquid limit (\%) & 28.2 \\
Plastic limit (\%) & 15.4 \\
Plasticity index (\%) & 12.8 \\
Liquidity index (\%) & 76.6 \\
Permeability coefficient $\left(10^{-4} \mathrm{~cm} / \mathrm{s}\right)$ & 7.36 \\
\hline
\end{tabular}

preparation. The moisture content and shear strength were tested in the same way at the same points after the impact test was completed and the impact column was removed.

3.2. Theoretical Impact Stress. It is assumed that the applied stress $(\sigma)$ is the sum of the static stress $(\Delta W)$ (the load due to the self-weight) and the dynamic stress $\left(F_{d} \Delta W\right)$ (along the direction of motion) [3]; that is,

$$
\sigma=\Delta W+F_{d} \Delta W
$$

The static stress can be determined from the weight/base area. Based on the impact column weight of $20.87 \mathrm{~kg}$ and the base diameter of $24 \mathrm{~cm}$, the theoretical static stress is $4.52 \mathrm{kPa}$. Dynamic stress can be determined by combining the conservation of kinetic energy and the momentum theorem $\left.\left(I=\int F d t=\Delta P\right)\right)$. Combined with its response time of $0.02 \mathrm{~s}$, the theoretical maximum dynamic stress can be calculated to be $72.25 \mathrm{kPa}$, and therefore the maximum theoretical total stress is $76.77 \mathrm{kPa}$.

\section{Results}

The total pressure and pore water pressure curves of the impact test results are shown in Figure 4 for soil samples at $5 \mathrm{~cm}, 15 \mathrm{~cm}$, and $25 \mathrm{~cm}$ depths and at 65\%,70\%, 75\%, 80\%, $85 \%$, and $90 \%$ saturation, respectively.

Figure 4 compares the total pressure and pore water pressure when the soil is impacted at different saturation levels. The curvilinear patterns of the total and pore water pressures are generally similar for each saturation condition. In general, both total pressure and pore water pressure undergo a transient increase and decrease at the moment of soil impact, which takes $40-60 \mathrm{~ms}$ to complete and only about $20 \mathrm{~ms}$ to peak. The curve fluctuates one or two more times over the next $200 \mathrm{~ms}$ and then remains stable. The instantaneous increase in superpore pressure at saturation levels of $65 \%$ and $70 \%$ is small, while the increase in pore pressure at saturation levels of $75 \%$ and above is significantly higher than the total pressure. The instantaneous increase in pore water pressure is small at saturations of $65 \%$ and $70 \%$, while it is significantly higher than the total pressure for soil with saturations of $75 \%$ and above. The fluctuations after the first peak are more pronounced at saturations of $65 \%, 70 \%$, $75 \%$, and $80 \%$, with peak fluctuations around $10 \mathrm{kPa}$, while the fluctuations of the total pressure and pore water pressure at $85 \%$ and $90 \%$ saturation are relatively weak. In order to better understand the pore water pressure peak law, the peaks are extracted as shown in Figure 5.

Figure 5 shows the peak pore pressure variation curve of each soil layer and saturation. It can be seen from the figure that the pore water pressure at the $25 \mathrm{~cm}$ depth shows a tendency to increase and then decreases with increasing saturation, reaching a peak value of more than $50 \mathrm{kPa}$ at $80 \%$ saturation and then decreasing sharply to only $8 \mathrm{kPa}$ at $90 \%$ 

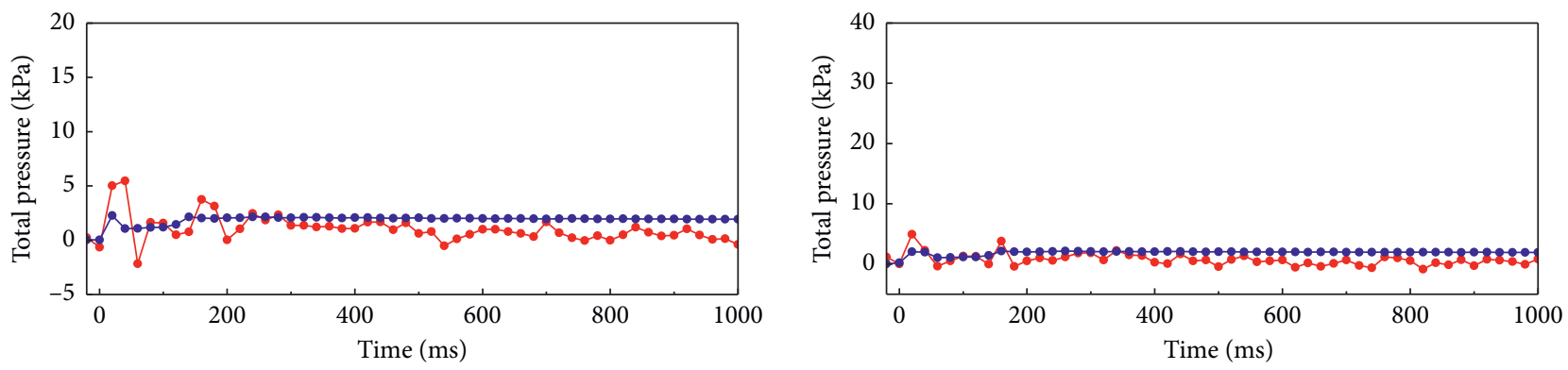

$\rightarrow$ S1

$\rightarrow S 1$

$\rightarrow$ P1
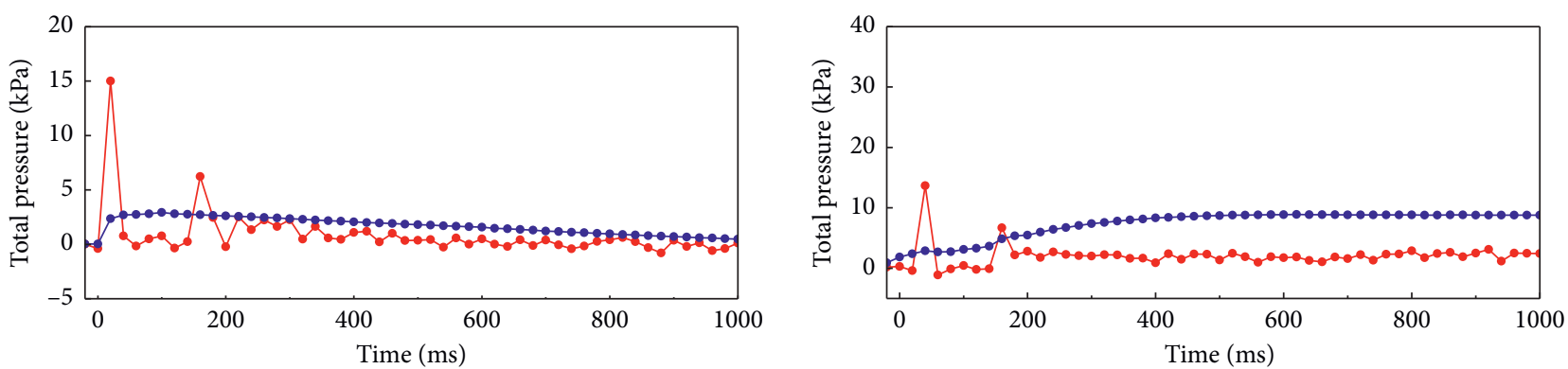

$\rightarrow$ S2

$\rightarrow \mathrm{S} 2$

$\rightarrow$ P2
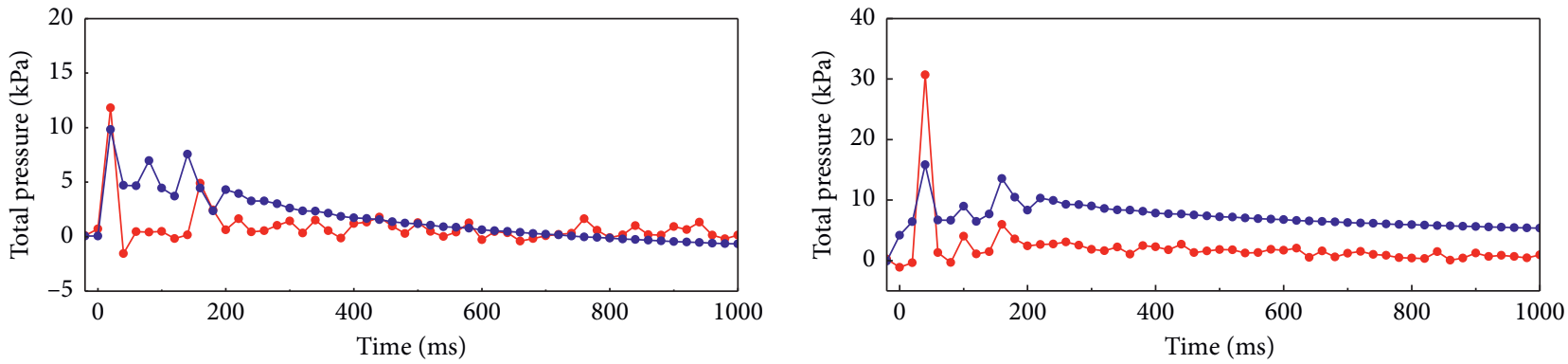

$\rightarrow \mathrm{S} 3$

$\rightarrow$ S3

$\rightarrow$ P3

(a)

(b)

Figure 4: Continued. 

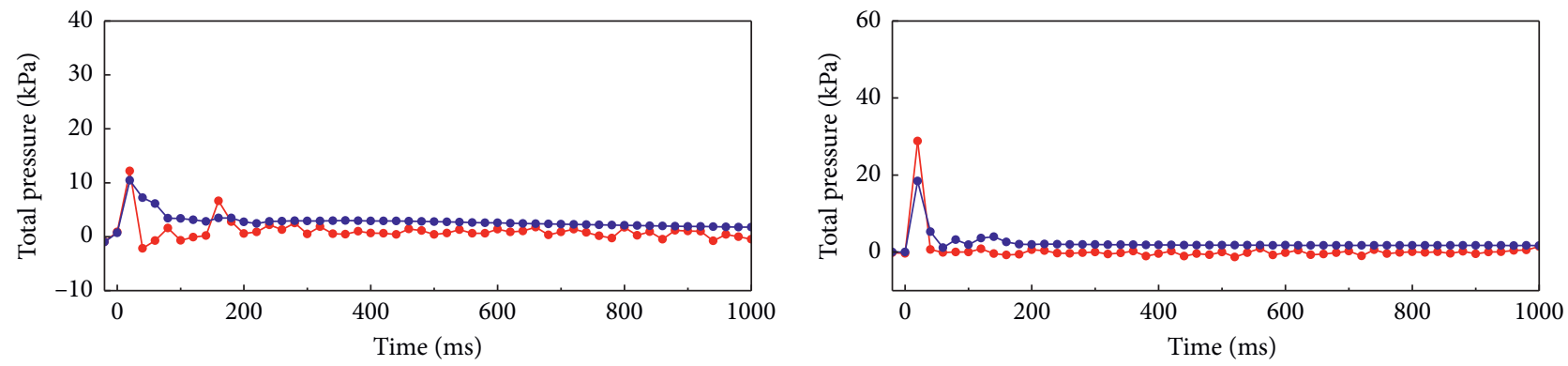

$\because \mathrm{S} 1$

$\rightarrow \mathrm{S} 1$

$\rightarrow \mathrm{P} 1$
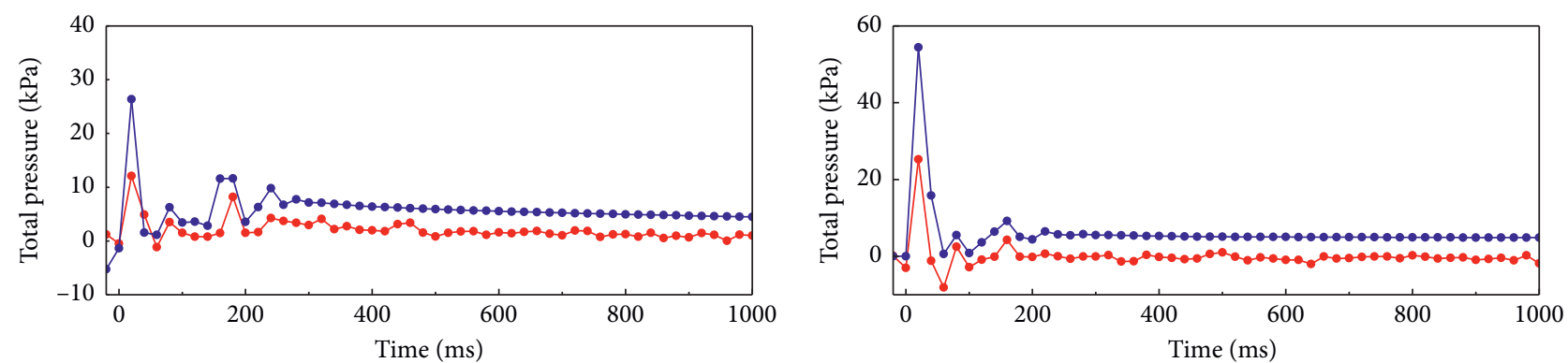

$\rightarrow \mathrm{S} 2$

$\rightarrow \mathrm{P} 2$

$\rightarrow \mathrm{S} 2$

$\rightarrow$ P2
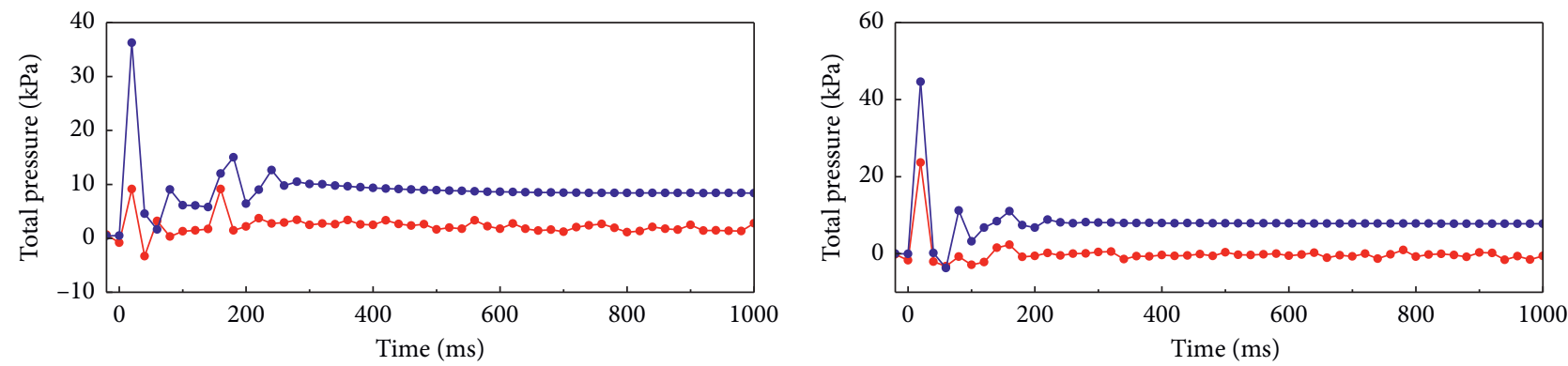

$\rightarrow$ S3

$\rightarrow \mathrm{P} 3$

$\rightarrow$ S3

- $\mathrm{P} 3$

(c)

(d)

Figure 4: Continued. 

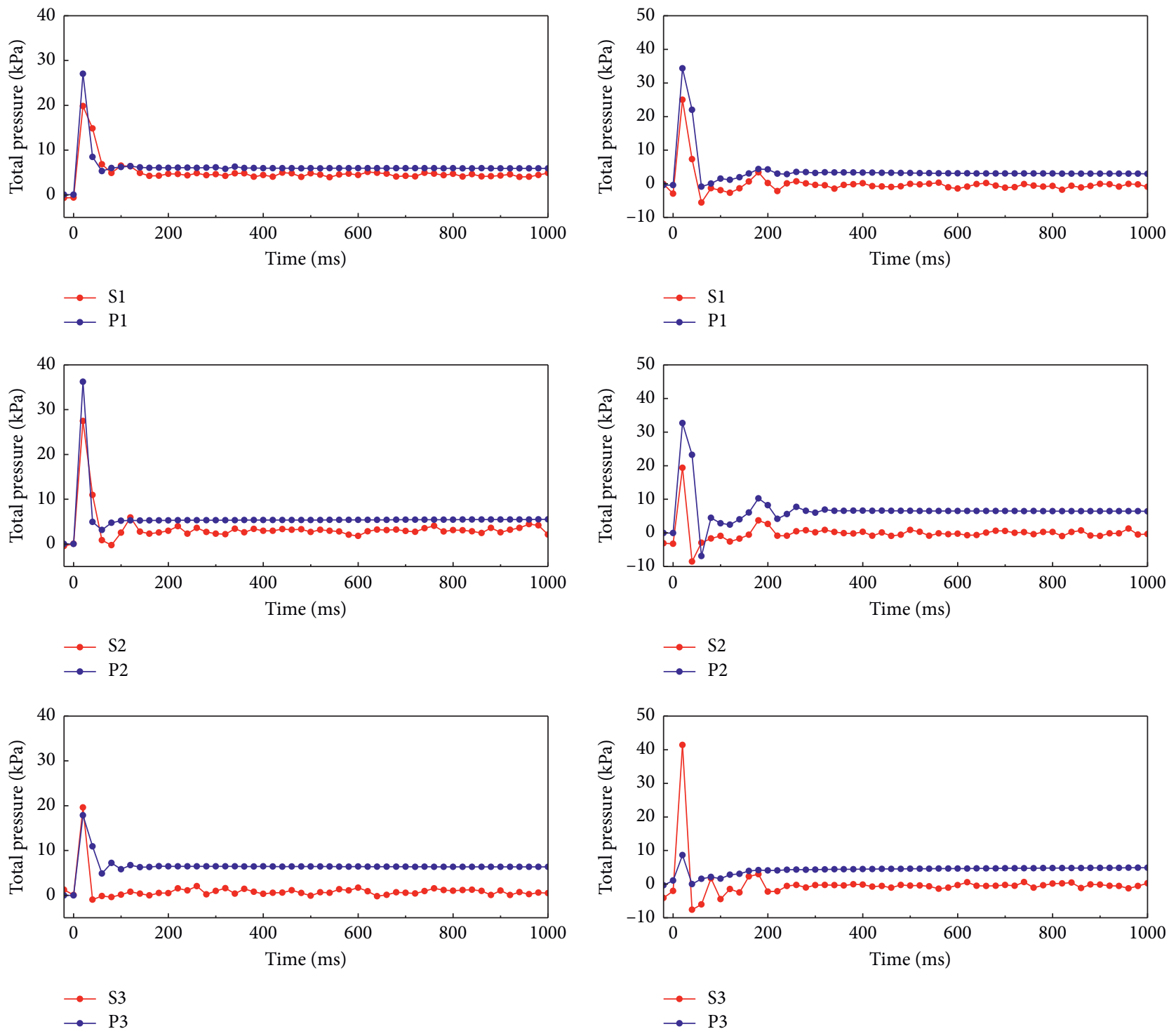

(e)

(f)

FIGURE 4: Total pressure and pore water pressure curves at different saturations and depths. (a) $65 \%$ saturation. (b) $70 \%$ saturation. (c) $75 \%$ saturation. (d) $80 \%$ saturation. (e) $85 \%$ saturation. (f) $90 \%$ saturation.

saturation. The pore water pressure at the $15 \mathrm{~cm}$ depth shows a similar tendency, reaching a maximum of $54 \mathrm{kPa}$ at $80 \%$ saturation and decreasing to $32 \mathrm{kPa}$ at $90 \%$ saturation. The pore pressure at the $5 \mathrm{~cm}$ depth shows a slowly increasing trend from less than $5 \mathrm{kPa}$ at $65 \%$ and $70 \%$ saturation to $34 \mathrm{kPa}$ at $90 \%$ saturation.

Figure 6 shows the variation characteristics of each degree of saturation at different depths. From this figure, it can be observed that soils at saturations of $65 \%, 70 \%$, and $75 \%$ have the lowest pore water pressure at $5 \mathrm{~cm}$ depth, and the peak pore water pressure increases with increasing depth. Saturations of $80 \%$ and $85 \%$ have the highest peak pore water pressure at $15 \mathrm{~cm}$ depth. Saturations of $90 \%$ have the lowest peak pore water pressure at $25 \mathrm{~cm}$ depth and the highest peak pore water pressure at $5 \mathrm{~cm}$ depth.
Figure 7 shows the comparison of moisture content and liquidity index before and after impact for different saturations at different depths. The liquidity index is calculated from the moisture content and soil liquid-plasticity limit. As shown in the figure, overall, the moisture content at $5 \mathrm{~cm}$ depth changes significantly after impact. The moisture content of the soil at $65 \%, 70 \%$, and $75 \%$ saturation decreased by 2 to $2.5 \%$, while the moisture content of the soil at $80 \%, 85 \%$, and $90 \%$ saturation increased significantly. The moisture content of soil at $80 \%$ saturation is extremely elevated by about $8 \%$. The moisture content at $15 \mathrm{~cm}$ depth changed slightly, while the moisture content at $25 \mathrm{~cm}$ depth changed very little.

Figure 8 shows the comparison of the shear strength before and after the impact of each saturation at different 


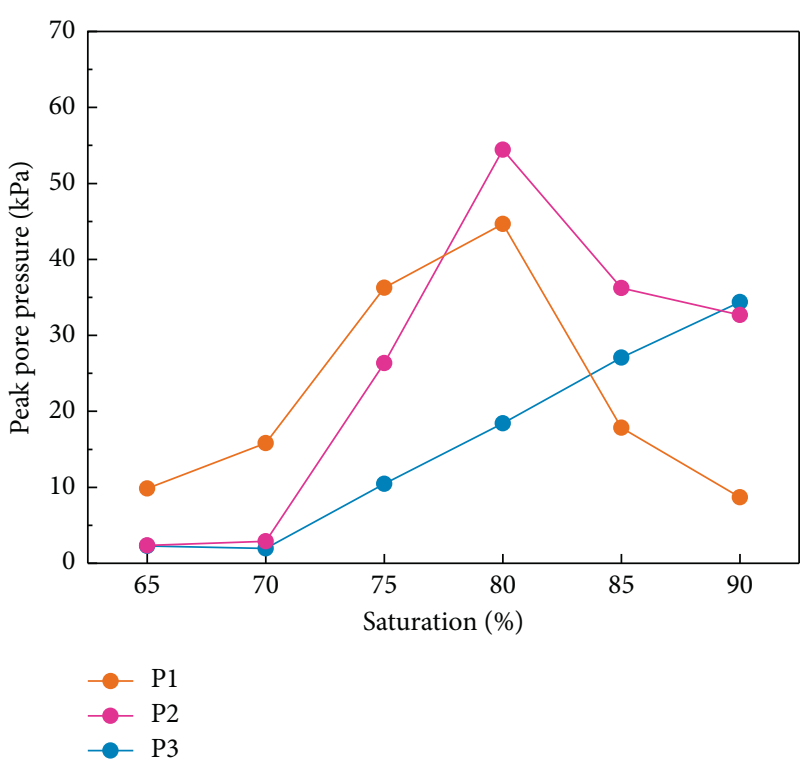

Figure 5: Peak value of pore pressure at different saturations and depths.
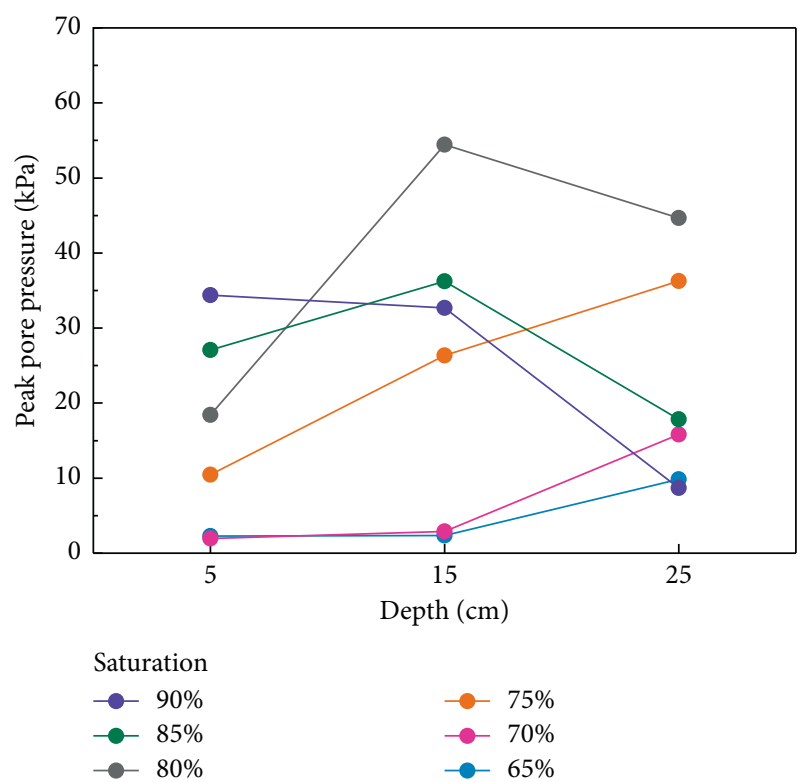

Figure 6: Peak value of pore pressure for different saturations at different depths.

depths. From Figure 8, it can be observed that as the saturation increases, the overall shear strength of the soil decreases. As the depth increases, the shear strength of the soil gradually increases. After impact, the shear strength of the low-saturation soil increases, while that of the high-saturation soil decreases. For soil at $75 \%$ saturation, shear strength at $5 \mathrm{~cm}$ depth decreases significantly. For soil at $80 \%$ saturation, the soil at $5 \mathrm{~cm}$ depth is close to the liquefied standard, while its shear strength decreases at $15 \mathrm{~cm}$ depth and increases at $25 \mathrm{~cm}$ depth. For soil at $85 \%$ and $90 \%$ saturation, the overall shear strength decreases to about $2.5 \mathrm{kPa}$.

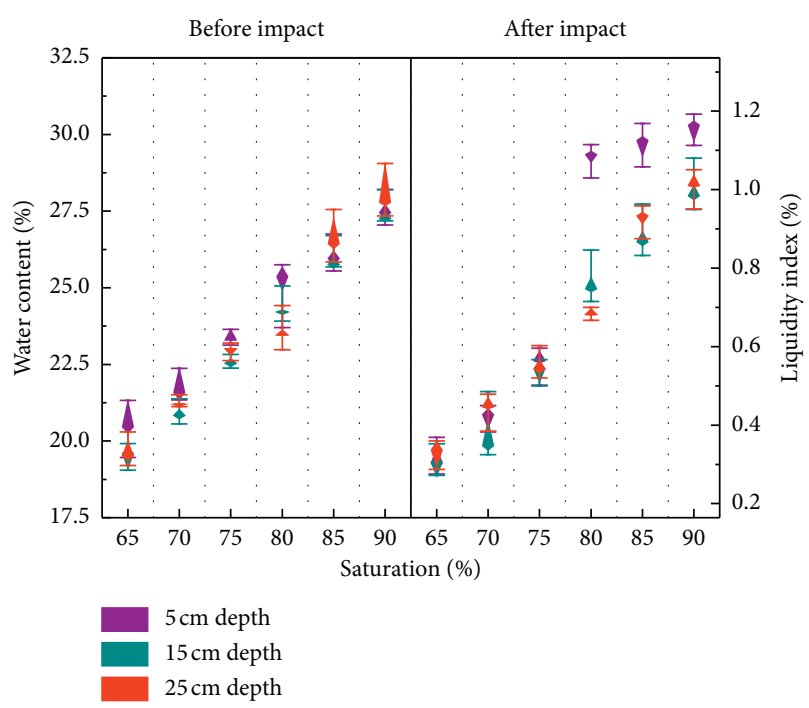

FIgURE 7: Moisture content and liquidity index curve.

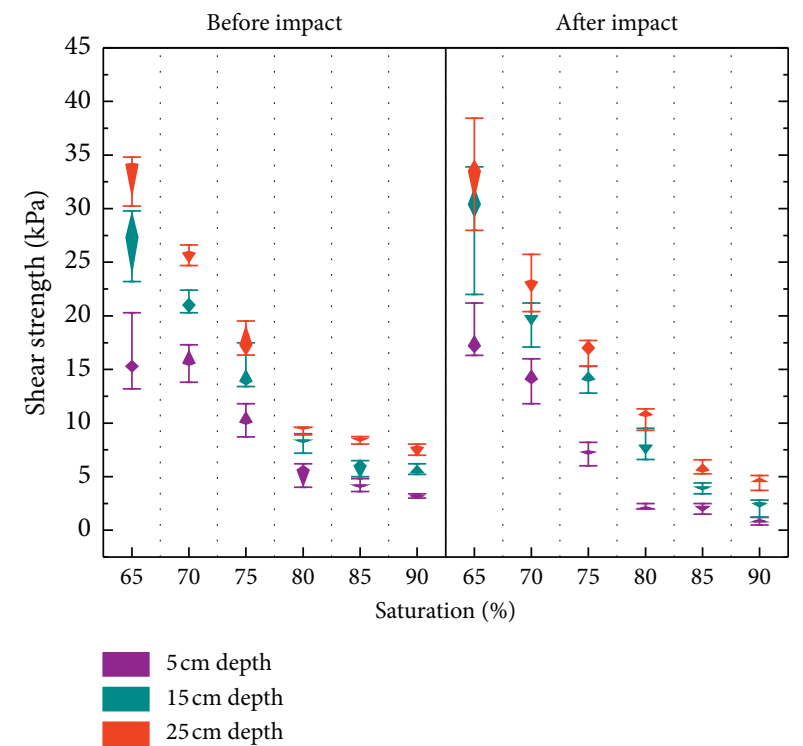

FIgURE 8: Shear strength curve of each saturation at different depths.

\section{Discussion}

5.1. Pore Water Pressure Changes under Impact. Pore water has always been one of the most important factors influencing the strength of soils. The rapid increase, rapid dissipation, and sudden stabilization of pore water pressure (see Figure 4) under impact indicate a rapid transition between the drained and undrained condition of the soil. During the short period of impact, the soil structure becomes denser [29]; the pore volume decreases [30]; the pore water pressure increases; and the soil changes from a drained condition to an undrained condition. In the process of decreasing pore water pressure, the soil changes back to a drained condition. In other words, the soil is temporarily in an undrained condition for the very short time it is impacted. It should be noted that the undrained condition refers to the state in 
which the pore water pressure rises sharply and the pore water is not fully drained in a short period of time. In the liquefied state, the permeability of the soil is $4-5$ times higher than in the initial state [31], and the change in the moisture content after the impact indicates that there is water migration in the soil in the undrained condition.

In general, the maximum pore water pressure depth in low-saturation soils is deeper than that in high-saturation soils under impact (see Figures 5 and 6). Under low-saturation conditions, the compression of the top soil layer and the increase in pore pressure do not cause liquefaction, and the stress therefore can be transferred to a deeper position. The top soil layer of a highly saturated soil body liquefies after impact, and a water film-a very common phenomenon in liquefaction under external loading [32] - is formed as the pore water pressure increases dramatically. Because of this, the impact force collapses in this layer and is difficult to transfer to the underlying soil, thereby not producing high pore water pressure in the lower soil.

5.2. Moisture Content and Shear Strength under Impact. Comparing the moisture content of each part of the soil body before and after impact (see Figure 7), it can be observed that the water migration that occurs within the soil body during this period is consistent with the rule that water migrates from a location with high pore water pressure to a location with low pore water pressure. For soil saturations of $65 \%, 70 \%$, and $75 \%$, the pore water pressure ratio is difficult to generate under impact, and water migration does not occur. For soils with $80 \%, 85 \%$, and $90 \%$ saturation, the pore water migrates from a high-pressure to a low-pressure position. This water migration is most apparent at a depth of $5 \mathrm{~cm}$.

The liquidity index above $5 \mathrm{~cm}$ depth at $80 \%$ and $85 \%$ saturation and above $15 \mathrm{~cm}$ depth at $90 \%$ saturation has exceeded 1 (see Figure 7). In other words, the moisture content has exceeded the liquidity limit, and the surface layer can reach as high as 1.2 after impact at $85 \%$ and $90 \%$ saturation. The soil at these locations has very low shear strength (see Figure 8) and is in a flow-like state. Some studies indicate that the shear strength of soils in the liquefied state ranges from 1.7 to $2.8 \mathrm{kPa}$ [33-36]. According to this criterion, liquefaction occurs above the depth of $5 \mathrm{~cm}$ at $80-85 \%$ saturation and above the depth of $15 \mathrm{~cm}$ at $90 \%$ saturation.

5.3. Mechanism of Impact-Induced Liquefaction. Particle size analysis shows that the sandy silt soil contains $55 \%$ of silt particles and $38 \%$ of sand particles. Most of the aggregate in the sandy silt structure is composed of silt and clay particles, and the clay particles often act as cement or coating for the silt particles (see Figure 9(a)) [37, 38]. Under the impact of the landslide thrust, the structure of silt and clay is disrupted and compacted [29], and the volume of the pores decreases (see Figure 9(b)) [30]. When the contact between the soil particles is completely replaced by pore water (see Figure 9(c)), the soil loses its shear strength and reaches the liquefied state. The soil in the liquefied state has a very high permeability coefficient [31], and the water inside the soil body migrates upward as the particles settle, resulting in high-moisture content in the upper soil layer (see Figure 9(d)).

\subsection{The Role of Impact-Induced Liquefaction Mechanism in} Long-Runout Landslides. The triggering mechanism of longrunout landslides has been the topic of much research in recent years, and the phenomenon of liquefaction triggered by landslides could be one of the important contributions. In this study, we investigated the liquefaction mechanism of soil under impact by using laboratory impact experiments, a moisture content test, and a vane shear test.

Similar landslide-triggered liquefaction phenomena have been studied for many years. For example, Sassa et al. studied landslide-triggered liquefaction in various locations, such as Hiroshima, Harihara, Fukushima, Gamahara, and Kameyama [3, 39-41]. Sassa et al. suggest that landslideinduced liquefaction is triggered by the undrained shear of the sliding surface created during the landslide. As the shear displacement of the shear zone increases, particle fragmentation leads to a decrease in the volume of the shear zone and to the liquefaction of the saturated shear zone. In their landslide citation study of Nagano, Japan, they found that the sliding surface liquefied at a normal stress of $47 \mathrm{kPa}$ during shear, indicating that a small force was enough to cause liquefaction to occur. Sassa et al.'s ring shear experiments provide a good representation of the development of liquefaction; however, they focus on the shear effect on the slip surface during landslides and neglect the possibility of liquefaction triggered by the impact of the slide's descent. The occurrence of liquefaction may be delayed due to the gradual increase of normal stress loading in the ring shear experiment. In this paper, it is suggested that the liquefaction of these landslides may have started at the moment of impact, and the shear of the sliding surface after the impact plays the role of continuous enhancement and facilitation of liquefaction. However, further research is needed.

The Oso landslide is a representative case of a landslide impact-induced liquefaction [5, 11-14, 42-45]. Iverson and George [42, 45] performed numerical simulations of the start-up and running of the Oso landslide. They speculated that the material in the slide could have liquefied and suggested that liquefaction could have occurred anywhere on the Oso landslide. This has been challenged by other scholars. It is now widely accepted that liquefaction only occurred in the loose slope deposits from the primary landslide. The latest landslides are unsaturated and hyperconsolidated and therefore do not undergo liquefaction $[5,13,14,44]$. Aaron [5] and Stark [44] suggest that liquefaction occurs partly due to the undrained load caused by the impact of the upper part of the landslide and partly due to the liquefaction produced by the deformation and rapid shear of the landslide. This view is consistent with the liquefaction mechanism described in this paper. Wartman et al. [14] presented a detailed landslide mechanism for the Oso landslide and further suggested that the liquefied soil was deposited by the 2006 landslide. This liquefaction did not 
(a)

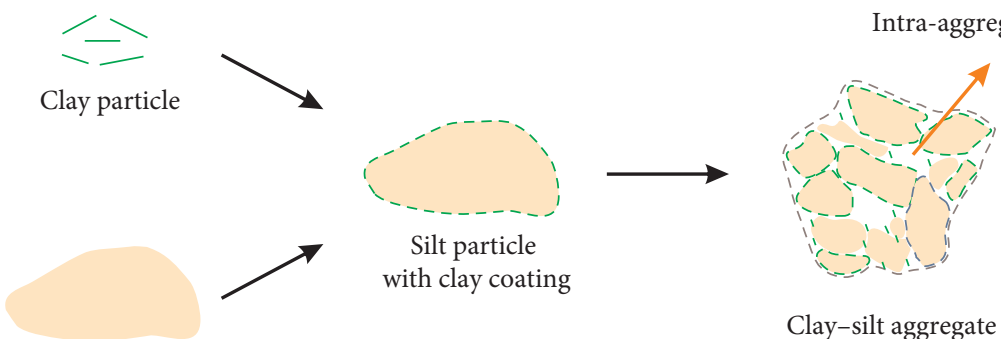

Silt particle

(b)

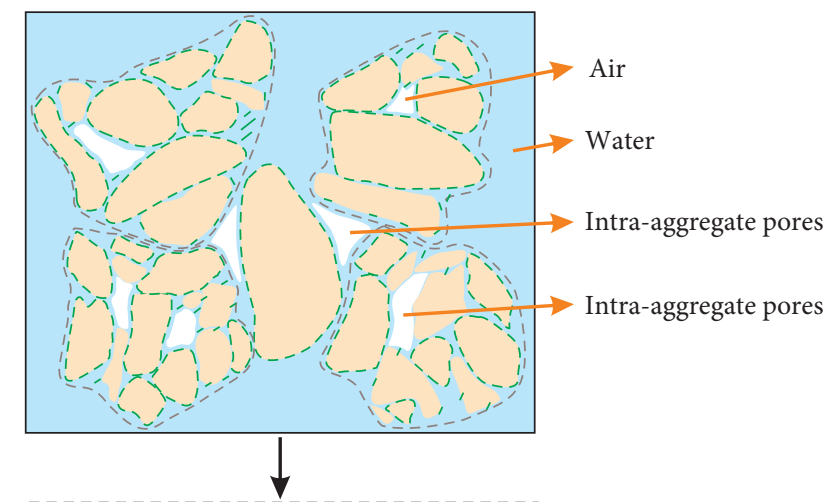

(c)

A representative volume element

(d)

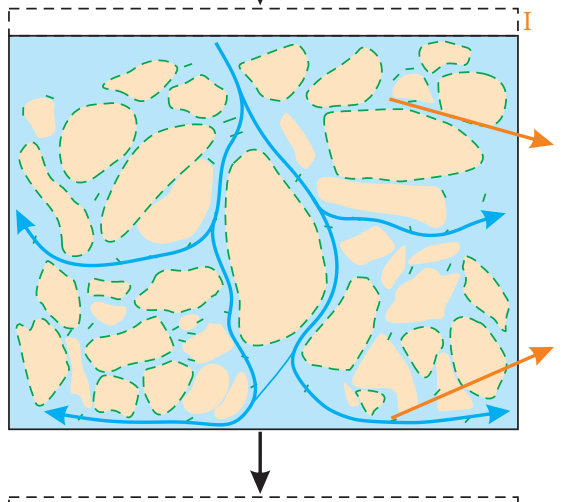

Impact settlement

Clay-silt aggregate structural collapse

Soil liquefaction after impacting

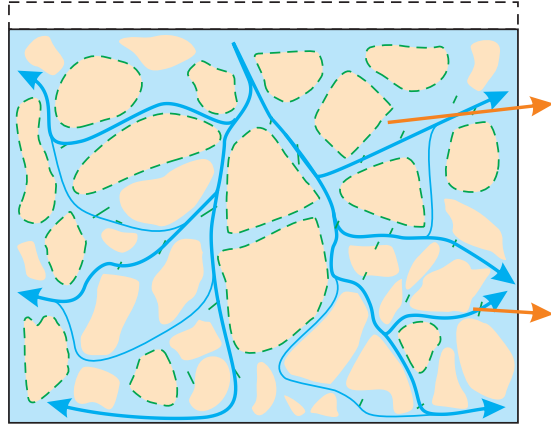

Dispersal of claysilt aggregates

Pore water flow trend breakage

Clay and silt particles flow with pore water

FIGURE 9: Schematic diagram of impact-induced liquefaction mechanism. 
only occur at the bottom of the landslide surface, but also extensively in the deeper, near-saturated loose sediment layers. It can be inferred that the occurrence of liquefaction is not entirely caused by undrained shear. The impact of the sliding mass on the deposits is also an important cause of liquefaction. Yerro et al. [13] simulated the landslide process using the material point method and compared the effects of the presence or absence of soil liquefaction on the runout distance to the landslide. They concluded that the relative importance of liquefaction on remote landslides needs further study because the sliding distance is significantly less than the observed sliding distance only when initial soil softening and liquefaction occur simultaneously.

This paper focuses on the effect of saturation on impactinduced liquefaction, but in reality, particle size grading, porosity, impact energy, and stratigraphic relationships are all factors that influence the impact-induced liquefaction, which requires further research to draw conclusions. In addition, the liquefaction mechanism of soil under shear, vibration, and impact is fundamentally different. Further exploration will help to determine whether a landslide has different runout distances when it is subjected to different combinations of liquefaction.

\section{Conclusion}

Through a series of experiments, this paper studies the pore water pressure of saturated sandy silt under impact, and the changes in its moisture content, liquidity index, and shear strength before and after impact. It reveals the development process of pore pressure and the response regulation of internal soil structures under impact and proposes a possible impact liquefaction mechanism. Synthesizing the experimental results, observations, and analyses, the following main conclusions are drawn:

(1) The soil reached its peak pore pressure $20 \mathrm{~ms}$ after impact then fell back to remain relatively stable after 40-60 ms. The peak pore pressure showed variations depending on the depth and degree of saturation. The peak pore pressure at $5 \mathrm{~cm}$ depth increases as saturation increases, while the peak pore pressure at $15 \mathrm{~cm}$ and $25 \mathrm{~cm}$ depth shows a trend of rising and then falling.

(2) At $5 \mathrm{~cm}$ depth, highly saturated soils show a significant increase in moisture content and a reduction in shear strength to liquefied levels after impact, while less saturated soils show a slight decrease in moisture content and little change in shear strength. For soils at depths of $15 \mathrm{~cm}$ and $25 \mathrm{~cm}$, the moisture content is only minimally altered. The shear strength of highly saturated soils decreases significantly, while the shear strength of less saturated soils remains unchanged.

(3) The structure of the silt and clay is disrupted and compacted under the impact of the landslide thrust. The pore volume also decreases in this process. As the contact between particles is completely replaced by pore water, the soil loses shear strength and reaches a liquefied state. The high permeability of the soil in this liquefied state and the difference in pore water pressure at different depths lead to water migration within the soil. The pore water migrates upward as the soil particles settle; therefore, the upper soil layer shows higher moisture content at high levels of saturation.

\section{Data Availability}

The data used to support the findings of this study are available from the corresponding author upon request.

\section{Conflicts of Interest}

The authors declare that they have no conflicts of interest regarding the publication of this paper.

\section{Acknowledgments}

This study would not have been possible without the financial support from the China Postdoctoral Science Foundation No. 2020M683676XB and Special Fund for the National Natural Science Foundation of China under Grant nos. 41790442, 41702298, and 41602359, as well as the project supported by the Natural Science Basic Research Plan in Shaanxi Province of China under Grant no. 2017JQ4020.

\section{References}

[1] S. J. Poulos, G. Castro, and J. W. France, "Liquefaction evaluation procedure," Journal of Geotechnical Engineering, vol. 111, no. 6, pp. 772-792, 1985.

[2] J. Peng, P. Ma, Q. Wang et al., "Interaction between landsliding materials and the underlying erodible bed in a loess flowslide," Engineering Geology, vol. 234, pp. 38-49, 2018.

[3] G. Wang, K. Sassa, and H. Fukuoka, "Downslope volume enlargement of a debris slide-debris flow in the 1999 Hiroshima, Japan, rainstorm," Engineering Geology, vol. 69, no. 34, pp. 309-330, 2003.

[4] P. Li, W. Shen, X. Hou, and T. Li, "Numerical simulation of the propagation process of a rapid flow-like landslide considering bed entrainment: a case study," Engineering Geology, vol. 263, Article ID 105287, 2019.

[5] J. Aaron, O. Hungr, T. D. Stark, and A. K. Baghdady, "Oso, Washington, landslide of March 22, 2014: dynamic analysis," Journal of Geotechnical and Geoenvironmental Engineering, vol. 143, no. 9, Article ID 05017005, 2017.

[6] Q. Zeng, L. Zhang, T. Davies et al., "Morphology and inner structure of Luanshibao rock avalanche in Litang, China and its implications for long-runout mechanisms," Engineering Geology, vol. 260, Article ID 105216, 2019.

[7] T. Li, P. Wang, and Y. Xi, "The mechanisms for initiation and motion of Chinese loess landslides," in Environmental Science and Engineering, Progress of Geo-Disaster Mitigation Technology in Asia, F. Wang, M. Miyajima, T. Li, W. Shan, and T. F. Fathani, Eds., no. 2, Springer, Berlin, Germany, pp. 105-122, 2013.

[8] K. Sassa, G. Wang, H. Fukuoka et al., "Landslide risk evaluation and hazard zoning for rapid and long-travel landslides 
in urban development areas," Landslides, vol. 1, no. 3, pp. 221-235, 2004.

[9] K. Sassa, G. Wang, and H. Fukuoka, "Performing undrained shear tests on saturated sands in a new intelligent type of ring shear apparatus," Geotechnical Testing Journal, vol. 26, no. 3, pp. 257-265, 2003.

[10] C. Kang, F. Zhang, F. Pan, J. Peng, and W. Wu, "Characteristics and dynamic runout analyses of 1983 Saleshan landslide," Engineering Geology, vol. 243, pp. 181-195, 2018.

[11] B. Henn, Q. Cao, D. P. Lettenmaier et al., "Hydroclimatic conditions preceding the March 2014 oso landslide*," Journal of Hydrometeorology, vol. 16, no. 3, pp. 1243-1249, 2015.

[12] B. D. Collins and M. E. Reid, "Enhanced landslide mobility by basal liquefaction: the 2014 State Route 530 (Oso), Washington, landslide, GSA Bulletin," Bulletin of the Geological Society of America, vol. 132, no. 3-4, pp. 451-476, 2020.

[13] A. Yerro, K. Soga, and J. Bray, "Runout evaluation of oso landslide with the material point method," Canadian Geotechnical Journal, vol. 56, no. 9, pp. 1304-1317, 2019.

[14] J. Wartman, D. R. Montgomery, S. A. Anderson et al., "The 22 March 2014 oso landslide, Washington, USA," Geomorphology, vol. 253, pp. 275-288, 2016.

[15] G. Wang, A. Suemine, F. Zhang, Y. Hata, H. Fukuoka, and T. Kamai, "Some fluidized landslides triggered by the 2011 tohoku earthquake ( $\mathrm{Mw}$ 9.0), Japan," Geomorphology, vol. 208, pp. 11-21, 2014.

[16] J. Peng, G. Wang, Q. Wang, and F. Zhang, "Shear wave velocity imaging of landslide debris deposited on an erodible bed and possible movement mechanism for a loess landslide in Jingyang, Xi'an, China," Landslides, vol. 14, no. 4, pp. 1503-1512, 2017.

[17] Z. Duan, W.-C. Cheng, J.-B. Peng, Q.-Y. Wang, and W. Chen, "Investigation into the triggering mechanism of loess landslides in the south Jingyang platform, Shaanxi province," Bulletin of Engineering Geology and the Environment, vol. 78, no. 7, pp. 4919-4930, 2019.

[18] F. Zhang and G. Wang, "Effect of irrigation-induced densification on the post-failure behavior of loess flowslides occurring on the Heifangtai area, Gansu, China," Engineering Geology, vol. 236, pp. 111-118, 2018.

[19] H. Liao, T. Li, and J. Peng, "Study of strength characteristics of high and steep slope landslide mass loess," Rock and Soil Mechanics, vol. 32, no. 7, pp. 1939-1944, 2011, in Chinese.

[20] Y. Leng, J. Peng, Q. Wang, Z. Meng, and W. Huang, “A fluidized landslide occurred in the Loess Plateau: a study on loess landslide in South Jingyang tableland," Engineering Geology, vol. 236, pp. 129-136, 2018.

[21] F. Yang, "Motion simulation of rapid long run-out loess landslide at dongfeng in Jingyang, Shaanxi," Journal of Engineering Geology, vol. 22, no. 5, pp. 890-895, 2014, in Chinese.

[22] W. Liu, S. He, and X. Li, "Numerical simulation of landslide over erodible surface," Geoenvironmental Disasters, vol. 2, no. 1, p. 19, 2015.

[23] X. Lei, "The hazards of loess landslides in the southern plateau of Jingyang County, Shaanxi and their relationship with the channel water into fields," Journal of Engineering Geology, vol. 3, no. 1, pp. 56-64, 1995, in Chinese.

[24] L. Xu, "Loess landslide types and topographic features at south Jingyang plateau, China," Earth Science-Journal of China University of Geosciences, vol. 35, no. 1, pp. 155-160, 2010, in Chinese.

[25] Z. Duan, W.-C. Cheng, J.-B. Peng, M. M. Rahman, and H. Tang, "Interactions of landslide deposit with terrace sediments: perspectives from velocity of deposit movement and apparent friction angle," Engineering Geology, vol. 280, Article ID 105913, 2021.

[26] Z. Duan, Y.-B. Wu, H. Tang, J.-Q. Ma, and X.-H. Zhu, “An analysis of factors affecting flowslide deposit Morphology using taguchi method," Advances in Civil Engineering, vol. 2020, p. 14, 2020.

[27] J. P. Bardet and M. Kapuskar, "Liquefaction sand boils in san francisco during 1989 loma prieta earthquake," Journal of Geotechnical Engineering, vol. 119, no. 3, pp. 543-562, 1993.

[28] T. L. Youd and M. J. Bennett, "Liquefaction sites, imperial valley, California," Journal of Geotechnical Engineering, vol. 109, no. 3, pp. 440-457, 1983.

[29] J. A. Yamamuro and P. V. Lade, "Static liquefaction of very loose sands," Canadian Geotechnical Journal, vol. 34, no. 6, pp. 905-917, 1997.

[30] Y.-N. Wei, W. Fan, N. Yu, L.-S. Deng, and T. Wei, "Permeability of loess from the South Jingyang Plateau under different consolidation pressures in terms of the three-dimensional microstructure," Bulletin of Engineering Geology and the Environment, vol. 79, no. 9, pp. 4841-4857, 2020.

[31] T.-S. Ueng, Z.-F. Wang, M.-C. Chu, and L. Ge, "Laboratory tests for permeability of sand during liquefaction," Soil Dynamics and Earthquake Engineering, vol. 100, pp. 249-256, 2017.

[32] T. Kokusho, "Water film in liquefied sand and its effect on lateral spread," Journal of Geotechnical and Geoenvironmental Engineering, vol. 125, no. 10, pp. 817-826, 1999.

[33] E. R. Russell and J. L. Mickle, "Liquid limit values by soil moisture tension," Journal of the Soil Mechanics and Foundations Division, vol. 96, no. 3, pp. 967-989, 1970.

[34] C. P. Wroth and D. M. Wood, "The correlation of index properties with some basic engineering properties of soils," Canadian Geotechnical Journal, vol. 15, no. 2, pp. 137-145, 1978.

[35] I. L. Whyte, "Soil plasticity and strength-a new approach using extrusion," Ground Engineering, vol. 15, no. 1, pp. 16-20, 1982.

[36] B. Sharma and P. K. Bora, "Plastic limit, liquid limit and undrained shear strength of soil-reappraisal," Journal of Geotechnical and Geoenvironmental Engineering, vol. 129, no. 8, pp. 774-777, 2003.

[37] Z. Liu, F. Liu, F. Ma et al., "Collapsibility, composition, and microstructure of loess in China," Canadian Geotechnical Journal, vol. 53, no. 4, pp. 673-686, 2016.

[38] T. Wei, W. Fan, N. Yu, and Y.-N. Wei, "Three-dimensional microstructure characterization of loess based on a serial sectioning technique," Engineering Geology, vol. 261, Article ID 105265, 2019.

[39] F. W. Wang, K. Sassa, and G. Wang, "Mechanism of a longrunout landslide triggered by the August 1998 heavy rainfall in Fukushima Prefecture, Japan," Engineering Geology, vol. 63, no. 1-2, pp. 169-185, 2002.

[40] K. Sassa, H. Fukuoka, and F. W. Wang, "Mechanism and risk assessment of landslide- triggered-debris flows: lesson from the 1996.12.6 Otari debris flow disaster, Nagano, Japan," in Landslide Risk Assessment, D. Cruden and R. Fell, Eds., pp. 347-356, Taylor \& Francis, Oxfordshire, UK, 1997.

[41] K. Sassa and G. Wang, "Mechanism of landslide-triggered debris flows: liquefaction phenomena due to the undrained loading of torrent deposits," in Debris-Flow Hazards And Related Phenomena, pp. 81-104, Springer, Berlin, Germany, 2007. 
[42] R. M. Iverson and D. L. George, "Modelling landslide liquefaction, mobility bifurcation and the dynamics of the 2014 Oso disaster," Géotechnique, vol. 66, no. 3, pp. 175-187, 2016.

[43] C. Hibert, C. P. Stark, and G. Ekström, "Dynamics of the OsoSteelhead landslide from broadband seismic analysis," Natural Hazards and Earth System Sciences, vol. 15, no. 6, pp. 1265-1273, 2015.

[44] T. D. Stark, A. K. Baghdady, O. Hungr, and J. Aaron, "Case study: oso, Washington, landslide of March 22, 2014-material properties and failure mechanism," Journal of Geotechnical and Geoenvironmental Engineering, vol. 143, no. 5, Article ID 05017001, 2017.

[45] R. M. Iverson, D. L. George, K. Allstadt et al., "Landslide mobility and hazards: implications of the 2014 Oso disaster," Earth and Planetary Science Letters, vol. 412, pp. 197-208, 2015. 